\title{
Análisis del discurso y archivos de la represión en Argentina
}

\author{
María Alejadra Vitale ${ }^{1}$
}

\begin{abstract}
Starting from Dominique Maingueneau's notion of discourse community, this article analyzes the "subversion" formula for constructing antiethos (or negative other) and ethos (or self-image) in documents from the archives of the Directorate of Intelligence of the Police of the Province of Buenos Aires (DIPBA) and the General Directorate of Information (DGI) of the Province of Santa Fe, both of which are now open for public consultation. It finds an interdiscursive relation between the two archives and the Doctrine of National Security so that the meaning of "subversion" is extended to include not only guerrilla groups and terrorism, but political, cultural and religious practices. It also notes that institutional differences between intelligence agents - police officers and members of the Armed Forces - affect the self-image they project.
\end{abstract}

Keywords: archive for repression; "subversion"; antiethos; ethos.

Resumen: Este artículo analiza la fórmula “(la) subversión”, en relación con la construcción del antiethos u otro negativo y del ethos o imagen de sí, en dos archivos de la represión abiertos para su consulta pública en Argentina: el de la Dirección de Inteligencia de la Policía de la Provincia de Buenos Aires (DIPBA) y el de la Dirección General de Informaciones (DGI) de la Provincia de Santa Fe. Parte de la noción de comunidad discursiva planteada por Dominique Maingueneau y constata que ambos archivos entablan una relación interdiscursiva con la Doctrina de la Seguridad Nacional, de modo que el sentido de la fórmula se amplía para incluir, además de la guerrilla y el terrorismo, la praxis política, cultural y religiosa. Constata, asimismo, que la diferencia institucional de los agentes de inteligencia -policías o miembros de las Fuerzas Armadas- incide en la imagen que dan de sí.

Palabras clave: archivos de la represión; subversión; antiethos; ethos.

\section{Introducción}

Se denominan "archivos de la represión" a los fondos documentales producidos por instancias represivas legales o ilegales de las fuerzas de seguridad que actuaron en la historia reciente de América latina y cuya consulta se hizo pública (Da Silva Catela y Jelin, 2002; Kahan, 2007; Karabibikián, 2007). El Archivo de la Dirección de Inteligencia de la Policía de la Provincia de Buenos Aires (DIPBA) y el Archivo de la Dirección General de Inteligencia (DGI) de la Provincia de Santa Fe son dos ejemplos en Argentina. En efecto, el Archivo de la DIPBA fue creado en 1956, durante la llamada Revolución Libertadora que derrocó a Juan Domingo Perón en 1955, y fue cerrado en 1998, en plena democracia que Argentina recuperó en 1983. Su consulta pública se hizo posible en 2003. El Archivo de la Dirección

1 Universidad de Buenos Aires. 
de General de Inteligencia (DGI) de la Provincia de Santa Fe fue creado en 1966, bajo la autodenominada Revolución Argentina encabezada por el general Juan Carlos Onganía, que derrocó ese mismo año al presidente radical Arturo Illia. Lo abrió el interventor militar a cargo de la gobernación de la Provincia de Santa Fe y funcionó hasta 1993, también hasta plena democracia. El acceso público a este archivo se hizo posible recién en 2011.

El archivo de la DIPBA y de modo incipiente el de la DGI han sido estudiados mayoritariamente desde la historia, la sociología y la antropología social y cultural (Águila, 2013, 2014: da Silva Catela, 2007; Flier, 2006; Funes, 2004, 2006; García, 2012, 2013; Kahan, 2007, 2011; Marengo, 2012; Scocco, 2012), de allí que hayan presentado un desafío para abordarlos desde el análisis del discurso. En este sentido, consideramos que la noción de comunidad discursiva que propone Dominique Maingueneau (1987, 1996, 1997) resulta fructífera para estudiarlos.

Maingueneau $(1987,1996,1997)$ denomina comunidad discursiva a un grupo u organización de grupos en el interior de los cuales son producidos y generados los textos que dependen de una formación discursiva. Una comunidad discursiva no se refiere únicamente a las instituciones y las relaciones entre los agentes sino también a todo lo que los grupos implican en el plano de la organización material y sus modos de vida. Maingueneau hace hincapié en que se trata de grupos que existen únicamente por y en la enunciación, en la gestión de textos, tal como sucede con los grupos de inteligencia que crearon los archivos de la DIPBA y de la DGI. En efecto, la noción de comunidad discursiva remite a un grupo o red de grupos productor de discursos de los que son indisociables sus prácticas y la propia existencia del grupo. Una comunidad discursiva incluye enunciadores que comparten valores, opiniones y un mismo posicionamiento, una identidad enunciativa fuerte que implica la intrincación de un modo de organización social y un modo de organización textual. El posicionamiento, que se delinea interdiscursivamente en un trabajo permanente de reconfiguración, entraña cierto ethos (Amossy, 2010; 2014), construido en oposición a un antiethos u otro negativo (Maingueneau, 1987).

El propósito de este artículo es así caracterizar el antiethos de las comunidades discursivas DIPBA y DGI en relación con la fórmula (Krieg-Planque, 2009, 2011, 2015) “(la) subversión”; antiethos en antagonismo con el cual se configura el ethos o imagen de sí de los agentes de inteligencia. Como corpus, consideramos una serie de documentos de ambos archivos fechados entre los primeros años de su apertura y la última dictadura militar que padeció Argentina (1976-1983). ${ }^{2}$

\section{Sobre "(la) subversión" en la DIPBA y en la DGI}

a nominalización “subversión”, precedida o no del artículo determinado, puede ser aborda desde la noción de fórmula acuñada por Alice Krieg-Planque (2009, 2011), es decir, una forma significante relativamente estable, frecuentemente expresada en una nominalización -como "(la) subversión”-, que circula en el discurso social. La circulación, sostiene Krieg-Planque (2009), puede implicar un cambio de lengua, como sucedió con la fórmula "totale Staat", que pasó del italiano al alemán y a la Falange española con "Estado totalitario", o un movimiento centro-periferia, sea entre lenguas diferentes o dentro de una misma lengua. Por otra parte, la fórmula condensa una ideología o posición política y se integra en una argumentación. La autora agrega que puede tener variantes o

2 Este trabajo presenta resultados de los proyectos de investigación UBACyT 20020150100238BA y PICT 2015/ 3712. 
ser objeto de reformulaciones - como "purificación étnica" / "limpieza étnica"- es fuente de polémicas y su sentido suele dar pie a disputas. En relación con su estudio de la fórmula "purificación étnica", Krieg-Planque (2015) observa que es posible encontrar lo que denomina un período preformulaico, que corresponde a la génesis de la fórmula.

En el Archivo de la DIBPA, se identifica, en un primer grupo de documentos fechados en $1956,{ }^{3}$ un período preformulaico que corresponde a la apertura del organismo de inteligencia policial, en el que los adjetivos "subversivo" y "subversiva" construyen un antiethos vinculado con la praxis gremial y política, con actividades del comunismo, el peronismo -proscripto electoralmente desde 1955- y de otros grupos políticos afines al peronismo que buscaban tomar el poder. ${ }^{4}$ Por ejemplo:

Esta unión /con los otros partidos disueltos (Peronista, Alianza Libertadora Nacionalista, y Socialista R. N.)/ es cada día más fuerte, y se manifiesta especialmente en el campo gremial y en las actividades subversivas. La ilegalidad del comunismo significará un agudizamiento del problema subversivo. ${ }^{5}$

En un segundo grupo de documentos, informes de inteligencia incluidos en legajos confeccionados entre 1961 y 1964, en el período inmediatamente posterior a la implementación del llamado Plan CONINTES ${ }^{6}$ - primera aplicación de la Doctrina de la Seguridad en la Argentina (García, 1991) -, se observa la progresiva cristalización de la fórmula "la subversión", como puede apreciarse en un informe de inteligencia fechado en 1961 -relativo al seguimiento de un militar que lideraba parte de la derecha peronista y se había sublevado contra el gobierno del presidente Arturo Frondizi, ${ }^{7}$ el general Miguel Ángel Iñíguez-:

El día miércoles 30 de agosto ppdo., se realizó una reunión entre dirigentes gremiales de la Pcia. de Córdoba y el General IÑíGUEZ. Según el informante, esta reunión se habría llevado a cabo en el paraje denominado "EL MOLINUEVO" después de La Falda y cuya duración fue de dos hs. y media. El mencionado General habría solicitado la colaboración de ellos para ultimar los preparativos de una subversión, pero éstos se habrían negado. ${ }^{8}$

En la cita, llama la atención el empleo del artículo indeterminado "una" -luego inusual en la fórmula- precediendo a "subversión". El sustantivo con determinante indefinido, como tipo de designación (Maingueneau, 2009), parece responder aquí a la concep-

3 Legajo DIPBA 277, Mesa Doctrina, folio 6; Legajo DIPBA 167, Mesa Doctrina, folios 25-26.

4 Para profundizar este estudio, ver Vitale y Bettendorff (2015).

5 Legajo DIPBA 277, Mesa Doctrina, folio 6.

6 El Plan o Estado CONINTES, "Conmoción Interna del Estado" fue introducido por el presidente Arturo Frondizi en 1958 y entró en vigencia en 1960, tras las huelgas de los trabajadores de la carne a raíz del intento de cierre del frigorífico Lisandro de la Torre; su aplicación fue también consecuencia de una serie de atentados atribuidos a comandos vinculados con la resistencia peronista. Durante su implementación, cientos de militantes fueron detenidos en cárceles o cuarteles militares y juzgados por tribunales castrenses sin defensa civil. Técnicamente, el Plan culminó en 1961 con la sanción del decreto 6.495/61, que derogó los anteriores, citando en su reemplazo la Ley 15.293 de Represión del Terrorismo -aprobada el 21 de julio de 1960-, con la que se ampliaban las facultades represivas y judiciales de las fuerzas armadas y se aumentaban las penas para casos de atentados y sabotaje. En 1962, durante la presidencia de José María Guido, volvió a declararse el Estado CONINTES como medida preventiva por varios meses (Damin, 2010).

7 Frondizi llegó al poder en mayo de 1958, representado a la Unión Cívica Radical Intransigente -UCRI-, gracias al voto del peronismo proscrito. Fue derrocado por un golpe de Estado en marzo de 1962.

8 Legajo DIPBA 7202, Mesa Referencia, folio 41. 
ción de lo subversivo como un modo de acción particular e individualizable, asimilado a las "actividades" referidas en los documentos de 1956; $;$ sin embargo, ya se ha introducido la nominalización "subversión" sustituyendo las formas adjetivadas anteriores.

Dos años más tarde, la fórmula "la subversión" es habitual en los enunciados producidos por los agentes de la DIPBA y otros organismos vinculados con ella. Es el caso de un informe referido a varios sospechosos de haber participado en un robo de armas efectuado el 25 de junio de 1963 en una fábrica de la Provincia de Buenos Aires:

Antes de continuar, se considera necesario destacar que todos los citados son elementos peronistas que actúan en la subversión y manifiestan pertenecer a la Juventud Peronista [...]. Resulta evidente que estamos en presencia de elementos ya conocidos por este Servicio y con frondosos antecedentes subversivos en esta Provincia y Policía Federal. ${ }^{10}$

Retorna aquí respecto de 1956 la construcción de lo subversivo con un sentido ligado a la praxis -“actúan"- y a la participación política - "elementos peronistas" -; el artículo definido "la" opera para llevar el sustantivo "subversión” a una dimensión más abstracta, concediéndole un valor genérico. ${ }^{11}$ Se observa además que en este informe cobra relevancia un componente no manifestado en los documentos de la década anterior: la juventud -“Juventud Peronista"-, estrechamente ligada a las condiciones sociohistóricas de producción del Archivo de la DIPBA, dado que la juventud comienza a tener, a partir de los años sesenta, un papel central en el escenario político argentino (Bonvillani et al., 2008).

En otro documento de la misma coyuntura del Plan CONINTES, se identifica que la fórmula "la subversión" se articula con la figura que Marc Angenot (1994) denomina amalgama, que consiste en unificar como enemigo a múltiples grupos de variadas ideologías:

Pese a las escisiones y desacuerdos en que se debate la EXTREMA IZQUIERDA, ya se trate de COMUNISMO, trotskismo, Nacionalismo Marxista, Peronismo Obrero Revolucionario o cualquier otra corriente exteriorizada, existe un "común denominador" que los amalgama: LA SUBVERSIÓN, LA PREPARACIÓN REVOLUCIONARIA, LA PROCLAMACIÓN DE LA CONFUSIÓN Y EL CAOS Y EL FERVOROSO DESEO DE LA CONQUISTA DEL PODER. Presupone esto aseverar que está definida la tónica de quienes preparan el clima de violencia y como no resulta desconocido que los extremos se unen y confunden, el cuadro insurreccional presenta a sus actores principales en oculta pero decidida complicidad: marxista, tacuara, nacionalista de izquierda, peronista, castrista, chinófilos, etc. 12

Retorna aquí, en relación con los documentos de 1956, el vínculo de la subversión con la ideología política y la aspiración a la toma del poder; la fórmula "la subversión" funciona, en este caso, como equivalente de "la preparación revolucionaria", "la proclamación de la confusión y el caos" y "el fervoroso deseo de conquista del poder". El tópico según el cual "los extremos se unen" sirve como soporte de la antes mencionada figura de la amalgama, que habilita integrar en "la subversión" ya no sólo al comunismo, al peronismo y a agrupaciones afines -como en 1956- sino también a otros movimientos político-ideológicos que van de la extrema izquierda a la extrema derecha, como Tacuara.

9 Según Maingueneau (2009), el artículo indefinido extrae de la clase indicada por el sustantivo un elemento particular que no fue indicado antes y que es identificado únicamente por su pertenencia a esta clase, lo que explica que este tipo de designación sea utilizado para introducir referentes nuevos en el discurso.

10 Legajo DIPBA 128, Mesa Ds, folio 93.

11 Maingueneau (2009) atribuye un valor genérico a los sustantivos precedidos por un artículo definido singular.

12 Legajo DIPBA 159, Carpeta Material Bélico, folio 132. 
Los agentes de la DIPBA, mediante la aticulación de significantes como "marxista", "tacuara", "castrista", entre otros citados, unifican al antiethos desde la denominada Doctrina de la Seguridad Nacional. Al mismo tiempo, de modo implícito, el ethos del agente de inteligencia se construye como no peronista y anticomunista, maduro, moderado, en tanto se apone a los extremos, no violento y defensor de la claridad y el orden.

En un documento fechado en 1981, durante la última dictadura militar, "Plan y programas de estudio", de la Escuela de Inteligencia, se destaca el Programa de la materia "Inteligencia V", dedicado a "Actividades subversivas":

Conceptos generales: a. Conceptos de Acción Subversiva y Guerra Revolucionaria. b. Etapas: Organización, infliltraciones, puntos vitales a infiltrar. Captación; Activistas y Agitadores. c. Terrorismo: Concepto selectivo, sistemático, efecto psicológico. d. Fuentes en que actúa la subversión y objetivos.

En la cita se observa que la fórmula "la subversión" es asociada -como sucede desde la apertura de la DIPBA- con la praxis ("actúa), a la que se suman ahora sus objetivos. A su vez, entra en una misma serie, en cuanto conceptos generales, no solo con "Guerra Revolucionaria" y "Terrorismo" sino también con "Activistas" y "Agitadores", lo que amplía su sentido a la dimensión de la actividad política. Por otra parte, en el documento analizado se observa que el sentido de la fórmula incluye también lo económico y lo religioso:

Otros aspectos subversivos: a. subversión económica b. Amnistía internacional; objetivos y actuación en Argentina. c. Tercermundistas políticos y religiosos. Conceptos y su relación con la doctrina social de la Iglesia. Actuación en la Provincia de Buenos Aires. d. Guerra semántica. Concepto y características. e. Análisis y significación de expresiones del marxismo. Teología de la Liberación - Montonero - Guerrillero - Tupamaro - Liberado - Ideología - Praxis - Dinamizar etc.

Para los agentes de la DIPBA, el tercermundismo tanto político como religioso es incluido como "otros aspectos subversivos" y es relacionado con la Doctrina Social de la Iglesia. En esta línea, sobresale el concepto de "guerra semántica", que da cuenta de la importancia otorgada por el servicio de inteligencia a la lucha simbólica por la asignación del sentido de las palabras. Dentro de las "expresiones del marxismo", la DIPBA considera a la "Teología de la Liberación" como equivalente de palabras usadas con referencia a integrantes de grupos de lucha armada, como "Montonero" y "Tupamaro". Esto indica de modo implícito que esa teología y esos grupos entrañaban una misma peligrosidad y tiende a unificar, como sucedió en los sesenta, al enemigo interno.

En el caso del Archivo de la Dirección General de Inteligencia de la Provincia de Santa Fe, se destaca un documento fechado en 1968, donde la fórmula "subversión" es vinculada con elementos de las villas de emergencia (fabelas). En efecto, el documento titulado "Guía temática para tareas de investigación", referido a dichas villas de emergencia, como "Conclusiones desde el punto de vista de la inteligencia", incluye el establecimiento de "Capacidades de los elementos que integran las VVEE en acciones pro, para y específicamente revolucionarias (subversión, infiltración, sabotaje, etc.)". Se observa aquí que "subversión" funciona como equivalente de "infiltración" y "sabotaje" y es asociada, de modo similar a la DIPBA, a acciones revolucionarias. ${ }^{13}$

13 Ver UC 458, Legajo 10, hoja 40. 
Por otra parte, se constata también que en 1968 el adjetivo "subversivos" funciona como un equivalente del adjetivo "políticos" cuando el documento titulado "Directiva estratégica militar PC 69", ${ }^{14}$ considera para el "Factor comunismo y castrocomunismo" la "Posible formación de frentes o absorción de sectores con fines políticos o subversivos". Esta relación de equivalencia entre "políticos" y "subversivos" es interesante porque en 1968 el gobierno militar encabezado por el general Juan Carlos Onganía, de tendencias corporativas, había disuelto todos los partidos políticos.

Asimismo, se destaca que en 1970 la fórmula "subversión" es ya equivalente de "terrorismo" y "guerrillerismo", como se lee en el "Plan de Información inmediata" formulado por el Director General de asuntos policiales del Ministerio del Interior y preservado en el archivo de la DGI: "Subversión-Terrorismo-Guerrillerismo". ${ }^{15}$ En 1971, en el programa de un curso de capacitación para los agentes de inteligencia de la DGI, la fórmula "subversión" es asociada al sintagma "Guerra Revolucionaria", en una clara interdiscursividad con la Teoría de la Seguridad Nacional, como sucede en la DIPBA. ${ }^{16}$ En esta línea, en el programa del curso se lee como tramo del contenido de la unidad "Ideología": "Los que rechazan las normas culturales establecidas y tienden a la subversión y a la revolución", donde "la subversión" funciona como un equivalente de "la revolución" y el sentido de aquella se amplía al ámbito cultural. De modo similar a la DIPBA, los agentes de la DGI construyen de sí implícitamente la imagen de defensores del orden establecido frente a un antiethos que impulsa la guerrilla, el terrorismo y la guerra revolucionaria.

En la DGI de la Provincia de Santa Fe sobresale un género discursivo que cohesionó a esa comunidad de inteligencia, ${ }^{17}$ el Panorama Semanal de la Jurisdicción, que los agentes de alta jerarquía le mandaban al gobernador de la Provincia de Santa Fe. En ellos se identifica que en 1978, durante la última dictadura militar iniciada en 1976 -al igual que en la DIPBA- un sector de la Iglesia católica fue construido como entiethos. En un ejemplar de estos Panoramas firmado por el propio Director General de Inteligencia son introducidas mediante el discurso referido las palabras de dos miembros de la Iglesia católica del momento no alineados con la dictadura. Se trata primero de las palabras del obispo de la provincia de Santa Fe, monseñor Zaspe. Zaspe integró un grupo de obispos que, una vez instalada la dictadura militar, recibió a los familiares de las víctimas del terrorismo de Estado, emprendió gestiones privadas a favor de ellas, siempre sin éxito, y formuló cuestionamientos sin alcanzar la mayoría en las asambleas episcopales; sin embargo, estos obispos nunca adoptaron una línea de denuncia pública y frontal a las violaciones de los derechos humanos cometidas por el régimen militar (Mignone, 1986).

El panorama semanal preservado en el Archivo de la DGI demuestra que a pesar de no ser explícito en sus críticas a la dictadura, Zaspe integró el antiethos de la comunidad de espías y fue asociado con la fórmula "la subversión". En efecto, el Director de ese organismo escribe:

Santa Fe: 19 dic.- El Obispo XXX sigue con sus "charlas", y por ahí dice: “Anoche estuvimos reflexionando sobre los problemas del país a la luz del Evangelio, los salarios, la inflación, las viviendas, los hospitales, el agro, la seguridad personal, los problemas morales, el mercantilismo deportivo y el prode". ¿Qué raro? XXX se "olvidó" de mencionar el

14 La sigla PC se refiere al Partido Comunista. Ver UC 24, D/SFE 188/68.

15 Ver UC 463, Legajo 7, hoja 18.

16 Ver UC 76, S.I. $1 / 71$, cde. 4.

17 Según Beacco (2004) los géneros discursivos contribuyen a la conformación de las comunidades discursivas, en relación con lo cual establece once descriptores para caracterizarlas. 
principal problema que enfrenta el país, y más la juventud- ya que el les habla a ellos- que es: la subversión en todos sus órdenes. ${ }^{18}$

Ya las comillas en la palabra "charla" expresan una discordancia ideológica con el estilo conversacional de las homilías más dialogadas de Zaspe, que buscaban una proximidad con su auditorio. Por otra parte, luego de la ironía en "¿Qué raro?", y de las comillas distanciadoras en "olvidó", que sobreentienden que el obispo no habló de "la subversión" adrede, el Director de los agentes de inteligencia lo refuta disociando la noción de problema en secundario y principal, donde ubica a "la subversión". El complemento "en todos sus órdenes" extiende el sentido de la fórmula "la subversión" de modo que implícitamente no se reduce a la guerrilla o la guerra revolucionaria sino que abarca otros ámbitos, como el político y cultural (este último fue también asociado en 1971 -vimos- con "la subversión").

Luego de referirse a las palabras de monseñor Zaspe, el Director de los agentes de inteligencia de la Provincia de Santa Fe comenta también titulares de los principales diarios que se refieren a palabras de otro miembro de la Iglesia católica no alineado de modo estrecho con la dictadura, el cardenal Primatesta. Primatesta fue elegido presidente de la Conferencia Episcopal en 1976 y, a diferencia de Zaspe, se declaró un crítico acérrimo de la Teología de la Liberación. Sin embargo, fue objeto de polémica por parte del director de los agentes de inteligencia de la DGI. En efecto, este afirma:

CORDOBA: 17 dic.- El Cardenal XXX "exhortó a prepararse para la Navidad" según un titular de "El país en la noticia" (18/XII); "XXX hizo un llamado por el alma y la Fe", según "La Razón" (18/XII); "Dijo Primatesta una oración por la Patria", tal el titulo de "La Nación" (19/XII). ${ }^{19}$

El Director de los agentes de inteligencia se distancia de Primatesta denominándolo con comillas "el ilustre prelado" e incorpora en estilo directo palabras que dijo el cardenal:

Cansancio, pesimismo, calamidades públicas, siembra entre nosotros el luto y el desaliento; las fuerzas humanas limitadas y débiles flaquean; se hace necesario levantar la cabeza con confianza y sin temor (...) sería interesante que este "príncipe de la Iglesia" hiciera un paralelo entre 1975 y 1977, de las calamidades de esa época y las de ahora, de lo que expresó entonces y lo que está diciendo ahora. ${ }^{20}$

El director de la DGI refuta al cardenal mediante la argumentación ad hominem, al dar a entender que Primatesta no denunció en 1975, durante el gobierno de Isabel Perón, derrocado por el golpe militar de 1976, el estado calamitoso del país y que fue menos crítico entonces que en el presente de 1977.

Por otra parte, el director de ese organismo de inteligencia niega lo dicho por los diarios y construye un ethos patriótico, mientras que el cardenal Primatesta queda asociado a la antipatria. En efecto, mediante el argumento de autoridad, el director cita al capitán de navío Rubén Chamorro - quien fue director de la Escuela de Mecánica de la Armada,

18 El Prode fue un juego muy popular en Argentina durante la década del setenta, que se basaba en el pronóstico sobre el resultado de los partidos de fútbol. Ver UC 183, Legajo 10, Panorama semanal no. 9, hoja 41. A causa de una ley de 2000 que protege los datos personales preservados en archivos, los nombres propios son tachados en los documentos que la DIPBA y la DGI entregan a los investigadores.

19 Ver UC 183, Legajo 10, Panorama semanal no. 9, hoja 41.

20 Ver UC 183, Legajo 10, Panorama semanal no. 9, hoja 41. 
uno de los centros de detención clandestina más emblemáticos de la dictadura- y acusa a Primatesta de estar con la antipatria:

No es cierto que XXX haya expresado una oración por la Patria, su pueblo y su gobierno. Con el Capitán de Navío CHAMORRO decimos: "El país todo está herido, no agonizante como preconizan agoreros que son precisamente responsables de las heridas". No es cierto, como expresara ese agorero con hábitos, que estemos cansados, pesimistas, desalentados, débiles, con la cabeza gacha y con temor; si así fuera el pueblo y sus autoridades no estarían con firmeza reconstruyendo todo lo destruido por el desgobierno, la inmoralidad, la subversión, el tercermundismo y la demagogia. ${ }^{21}$

Se repite, asimismo, en un estilo bien polémico, el ataque ad personam hacia el cardenal Primatesta, denominado de modo despectivo "agorero con hábitos" por el Director de la DGI. El Director se incluye en un nosotros que es la contracara de la imagen de la comunidad nacional que dio Primatesta, una imagen positiva que destaca la firmeza y la unión del pueblo y el gobierno (militar). En el discurso del director de la DGI, la fórmula "la subversión" funciona como equivalente de desgobierno, inmoralidad, demagogia y tercermundismo, implícitamente asociado al gobierno de Isabel Perón y al propio cardenal Primatesta. El ethos inherente al nosotros en el que se incluye el Director de la DGI, en cambio, adquiere de modo implícito los sentidos positivos del gobierno, la moralidad, la no demagogia y de "occidente".

\section{Conclusiones}

A partir del análisis realizado, es posible plantear que las comunidades discursivas que produjeron los archivos de la DIPBA y de la DGI de la Provincia de Santa Fe se constituyeron como tales en una disputa por la hegemonía delimitándose de comunidades enemigas, otras, asimismo construidas en esa disputa en cuanto tales. Los diversos sentidos que adquirió la fórmula "(la) subversión" en ambos organismos y en distintos momentos de la historia argentina manifestaron los modos en que la propia identidad del nosotros de los agentes de inteligencia, su ethos, se conformó en relación antagónica con un antiethos.

La construcción de este antiethos se realizó en interdiscursividad con la Teoría de la Seguridad Nacional, de modo que tanto en la DIPBA como en la DGI la fórmula "(la) subversión" no se redujo a su asociación con la revolución y el guerrillerismo, sino que se amplió a la praxis política, cultural y religiosa, legitimando las prácticas represivas contra los diversos sectores de la población civil. El tercermundismo, tanto en su dimensión política como religiosa, fue contemplado asimismo como parte del antiethos.

En cuanto al ethos, se advierte que la imagen de sí que construyen los agentes en el género panorama semanal de la DGI es diferente al que se configura en los documentos de la DIPBA. En efecto, el ethos de estos panoramas incluye-vimos- un tono polémico, burlón, irónico, de cierta superioridad ante los discursos comentados o los personajes involucrados en los hechos narrados. Esta diferencia de tono puede deberse a las siguientes razones. Por un lado, en la DGI los agentes no fueron policías sino militares retirados, lo cual implicó una superioridad institucional, puesto que las Fuerzas Armadas frente a la policía tienen mayor poder en el orden jerárquico de las fuerzas represivas; por otra parte, han dado presidentes y cuadros que ocuparon puestos de relevancia en las dictaduras.

21 Ver UC 183, Legajo 10, Panorama semanal no. 9, hoja 42. 
Por otra parte, el propio enunciador tuvo un cargo jerárquico dentro de la DGI, puesto que el panorama aquí analizado fue escrito por su director.

Por último, se constata que, como plantea Maingueneau (1987), una comunidad discursiva es inseparable de una memoria. Se trata de la memoria discursiva, entendida como la repetición, reformulación u olvido, en una nueva coyuntura, de discursos ya dichos con anterioridad (Courtine, 1981, 2006). La memoria discursiva que conformó a las comunidades de la DIPBA y de la DGI no sólo estuvo integrada por un antiethos sino también por la imagen de sí o ethos que los agentes de inteligencia construyeron en sus discursos.

En relación con ello, como tarea pendiente para futuros trabajos se vislumbra el estudio, en esas comunidades discursivas dedicadas a la inteligencia, del progresivo olvido de la fórmula “(la) subversión” a partir de 1983, cuando Argentina recuperó la democracia.

\section{Referencias}

ÁGUILA, Gabriela. Las tramas represivas: continuidades y discontinuidades en un estudio de caso. La Dirección General de Informaciones de la Provincia de Santa Fe, 1966-1991, Sociohistórica, n. 31, 2013. Consultado de <http://www.sociohistorica. fahce.unlp.edu.ar/article/view/SHn31a01/3049>.

. La Universidad Nacional de Rosario en Dictadura (1976-1983): depuración, 'normalización' y reestructuración institucional. PolHis, v. 7, n. 14, 2014, p. 146-178. AMOSSY, Ruth. La présentation de soi. Éthos et identité verbale. Paris: PUF, 2010. . L'éthos et ses doubles contemporains. Perspectives disciplinaires. Langage et Societé, n. 149, 2014, p. 13-30.

ANGENOT, Marc. Les ideólogies du ressentiment. Montreal: XYZ Éditeur, 1994. BEACCO, Jean-Claude. Trois perspectives linguistiques sur la notion de genre discursif. Langages, n. 153, 2004, p. 109-119.

BONVILLANI, Andrea. et al. Juventud y política en la Argentina (1968-2008). Hacia la construcción de un estado del arte. Revista Argentina de Sociología, v. 6, n. 11, 2008, p. 44-73.

COURTINE, Jean-Jacques. Quelques problèmes théoriques et méthodologiques en analyse du discours, à propos du discours communiste adressé aux chrétiens. Langages n. 62,1981, p. 9-128.

. Metamorfoses do discurso político: derivas da fala pública. São Carlos: Claraluz, 2006.

DA SILVA CATELA, Ludmila. Etnografía de los archivos de la represión en la Argentina. In: FRANCO, M.; LEVÍN, F. (Comp.). Historia Reciente. Perspectivas y desafíos para un campo en construcción. Buenos Aires: Paidós, 2007, p. 183-220. DA SILVA CATELA, Ludmila; JELIN, Elizabeth (Comp.). Los archivos de la represión: documentos, memoria y verdad. Buenos Aires: Siglo XXI, 2002.

DAMIN, Nicolás. Plan Conintes y resistencia peronista 1955-1963. Buenos Aires: Instituto Nacional Juan Domingo Perón, 2010.

FLIER, Patricia. El archivo de la DIPBA: un hallazgo clave para una historia de los imaginarios represivos en Argentina. IMAGO AMERICAE, Revista de estudios del imaginario, v. I, n. 1, 2006, p. 225-238.

FUNES, Patricia. Medio siglo de represión. El Archivo de la Dirección de Inteligencia de la Policía de la provincia de Buenos Aires. Revista Puentes, n. 11, 2004, p. 34-43. 
. Secretos, confidenciales y reservados. Los registros de las dictaduras en la Argentina. El Archivo de la Dirección de Inteligencia de la Policía de la Provincia de Buenos Aires. In: QUIROGA, H.; TCACH, C. (Comp.). Argentina 1976-2006. Entre la sombra de la dictadura y el futuro de la democracia. Rosario: HomoSapiens, 2006, p. 199-232.

GARCÍA, Alicia. La doctrina de la Seguridad Nacional. Buenos Aires: Centro Editor de América Latina, 1991.

. Archivos y memorias. El caso "Vigil" y el corpus "reaparecido". Corpus, v. 3, n. 2, 2013, p. 2-33.

GARCÍA, Natalia. Una agenda pendiente: delitos culturales y económicos durante la última dictadura militar argentina.

El caso de la "Biblioteca Vigil" de Rosario (1977-2011). Información, Cultura y Sociedad n. 26, 2012, p. 41-64.

KAHAN, Emmanuel. ¿Qué represión, qué memoria? El 'archivo de la represión de la DIPBA': problemas y perspectivas. Questión, v. 1, n. 16, 2007, p. 1-10.

. De la conspiración al deicidio. Los judíos en los informes de la Dirección de Inteligencia de la Policía de la Provincia de Buenos Aires (DIPBA). Estudios Interdisciplinarios de América y el Caribe, v. 21, n. 2, 2011, p. 1-20.

KARABIBIKIÁN, Graciela. Archivos y Derechos Humanos en Argentina. Boletín del Archivo General de la Nación Año LXIX, v. XXXII, n. 119, 2007, p. 619-643.

KRIEG-PLANQUE, Alice. La notion de "formule" en analyse du discours. Cadre théorique et méthodologique. Besançon: Presses Universitaires de FrancheCompté, 2009.

. "Fórmulas" e "lugares discursivos": propostas para a análise do discurso político. In: MOTTA, Ana Raquel; SALGADO, Luciana (Org.). Fórmulas discursivas. São Paulo: Contexto, 2011.

Trabalhar os discursos na pluridisciplinaridade: exemplos de uma "maneira de

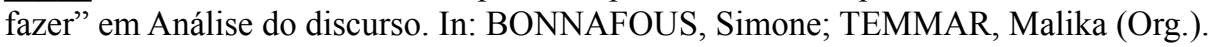
Análise do discurso, ciências humanas e sociais. São Carlos: Pedro e João, 2015. MAINGUENEAU, Dominique. Nouvelles tendances en analyse du discours. Paris: Hachette, 1987. . Les termes clés de l'analyse du discours. Paris: Seuil, 1996. . L'analyse du discours: introduction aux lectures del'archive. Paris: Hachette, 1997. . Análisis de textos de comunicación. Buenos Aires: Nueva Visión, 2009.

MARENGO, María Eugenia. Lo aparente como real: Un análisis del sujeto 'comunista' en la creación y consolidación del servicio de inteligencia de la policía de la Provincia de Buenos Aires. Tesis de Maestría en Historia y Memoria, Universidad Nacional de La Plata, 2012.

MIGNONE, Emilio Fermín. Iglesia y dictadura. El papel de la Iglesia a la luz de sus relaciones con el régimen militar. Buenos Aires: Editorial de la Universidad Nacional de Quilmes, 1986.

SCOCCO, Marianela. Reconstrucción de la Central de Inteligencia de la Provincia de Santa Fe sobre las reuniones y actos realizados en homenaje a los asesinados de Trelew en el primer aniversario de la massacre. Revista Electrónica de Fuentes y Archivo, v. 3, n. 3, 2012, p. 267-274.

VITALE, María Alejandra; BETTENDORFF, María Elsa. Memoria discursiva de 'la subversión’ según la DIPBA. Estudios del Discurso, v. 1, n. 2, 2015, p. 1-21. 